\title{
PRESENTACIÓN DEL LIBRO: \\ Politicas educativas culturalmente inclusivas. Red \\ Huaycán educa
}

Mercedes Giesecke Sara-Lafosse

Dado el momento histórico dentro del cual vivimos, el sistema de gobierno democrático y la globalización han creado una coyuntura propicia para reflexionar sobre los derechos culturales, que son parte de los derechos humanos. Se ofreció una oportunidad de investigar sobre los derechos culturales en Huaycán, población de raíces migrantes andinas, tomando como eje las escuelas públicas y sus proyectos educativos institucionales.

En el año 2006, a causa de la necesidad de conocer de qué manera se consideraban los temas culturales dentro de las escuelas públicas dirigí una investigación etnográfica para conocer el diagnóstico cultural de políticas culturales explícitas dentro de algunas de las escuelas públicas de Huaycán. Como conclusión pude constatar que básicamente se mantiene una tradición general de desarrollar todos los temas de la cultura andina en actividades extracurriculares sobre todo en las celebraciones con danzas, canciones y comidas, salvo algunas excepciones en las que se desarrollan temas andinos como el taller de arqueología en la IE Mixto Huaycán. A raíz de esta investigación tomé contacto con la Dirección de Promoción Escolar Cultura y Deporte-DIPECUD- del Ministerio de Educación, para hacer un taller con docentes de seis Instituciones Educativas de Huaycán donde se fueron reforzando los primeros hallazgos de la propia invisibilización de los temas culturales dentro de los planes de trabajo de las escuelas.

En dicha propuesta hubo algunas ideas eje como la posibilidad de crear un espacio sociocultural a través de una Red de Instituciones Educativas para que a través de ella se pudieran formular políticas educativas culturalmente inclusivas, las cuales debieran ser un nivel de reflexión y profundización desde lo particular de la localidad de Huaycán, así como de las grandes políticas educativas del país. En ellas debiera haber objetivos de inclusión cultural y de desarrollo humano como base contextual 
de la educación, asumiendo un sentido de responsabilidad compartido entre las IIEE participantes. Sus temas y metodologías propuestos están recogidos en este manual de la experiencia de la Red ¡Huaycán Educa! y han concitado el interés de los docentes por participar en un espacio que reconocen como suyo, en el cual se sienten exigidos para reflexionar y proponer nuevas metas comunes para el trabajo educativo en Huaycán, complementando y no interviniendo en la labor de la UGEL 06.

Para el año 2008 se conformaron las cinco comisiones temáticas y sus planes de trabajo respectivos, sin embargo aún quedan tareas estratégicas pendientes como fortalecer las vínculos con dos instancias centrales: el propio MINEDU a través de su apoyo con especialistas de la sede central y de la propia UGEL 06; por otro lado estableciendo vínculos más estrechos con la Municipalidad de Ate y su Agencia Municipal de Huaycán, para establecer objetivos comunes en los respectivos planes de trabajo sobre la mejora educativa. Así mismo entretejer alianzas estratégicas con instituciones de desarrollo local en Huaycán y con otras IIEE que vayan buscando crear planes específicos sobre temas comunes, motivando y reforzando la agencia en los docentes y devolviéndoles el liderazgo e iniciativa que los maestros deben tener en el desarrollo de sus propias comunidades, en donde viven y trabajan, saliendo del aislamiento e intercambiando sus experiencias exitosas y enfrentando de manera conjunta las debilidades que amenazan conquistar a la sociedad de Huaycán en la tarea conjunta por la educación, porque la educación es tarea de todos.

El objetivo primordial este proyecto piloto fue demostrar que la colaboración entre las IIEE y el intercambio de las buenas prácticas educativas, era posible de ser coordinado y provocar una buena expectativa entre los docentes quienes en todo momento se mostraron interesados en participar con demostraciones sobre cómo desarrollar el proceso de enseñanza aprendizaje. Sobre todo en un contexto adverso donde la pobreza material se entrelaza de manera negativa con el desarrollo de las metas del sistema educativo. En este sentido la red ¡Huaycán educa!, se constituiría en una propuesta práctica para impulsar una mayor adecuación de la educación al contexto cultural.

Como parte de la estrategia de investigación se realizaron etnografías sobre las fortalezas en diferentes ámbitos de la educación: a. Técnica y para el Trabajo; b. De la identidad y del sentido de pertenencia; $\mathrm{c}$. de una cultura de comprensión lectora y del hábito lector; d. de la promoción de la calidad de vida con la mejora del medio ambiente; e. de la violencia y educación en la paz. Estas etnografías cumplieron un rol muy importante de fundamentar la importancia de cada una de las cinco comisiones temáticas.

En el proceso de conformación de la Red Huaycán Educa, se le dio un papel estratégico a la cultura a través de temas como Cultura y desarrollo bumano: Desarrollo humano; La diversidad cultural andina en Lima; Derechos culturales; Realidad sociocultural de Huaycán. Otro tema: La educación y la cultura: La cultura como base para la educación; Valcárcel y Arguedas y el esfuerzo del Estado peruano por dar un contexto cultural a la educación; Los derechos culturales en relación a la educación básica en el Perú. 
La creación de una red fue necesaria como fundamento para la creación de nuevas relaciones humanas en Huaycán en relación a:

1) El desarrollo de la confianza que refuerza y promueve la creación de una identidad cultural que se proyecta a una visión compartida de acción y de mejora educativa.

2) La capacidad de hacer fluir información, mayor coordinación y comunicación, creando un nuevo escenario para dialogar y proponer objetivos y sugerencias para los planes de trabajo anuales de la II. EE. en Huaycán. Generando así, un modelo cultural para colaboraciones futuras, creando una mayor conciencia del aporte personal e institucional para lograr beneficios colectivos.

3) La posibilidad de contribuir a que el resultado de la educación sea más satisfactoria. El éxito académico está relacionado a la formación de vínculos entre alumnos, maestros, padres e instituciones locales. A través de los cuales se desarrolla la reciprocidad de conocimientos y relaciones humanas. Promoviendo un mejor desempeño de la comunidad en su conjunto a favor de la educación y de la cultura a través del intercambio de experiencias exitosas.

Cabe terminar agradeciendo, la dedicación y empuje de los alumnos y egresados de antropología de San Marcos, quienes dieron lo mejor de sí para la realización del trabajo de campo y la sistematización de las etnografías. 